University of Nebraska - Lincoln

DigitalCommons@University of Nebraska - Lincoln

2006

\title{
The Effects of Prejudice Level and Social Influence Strategy on Powerful People's Responding to Racial Out-Group Members
}

Theresa K. Vescio

Pennsylvania State University

Sarah J. Gervais

Pennsylvania State University, sgervais2@unl.edu

Swen Heidenreich

Philipps-Universität Marburg, Germany

Mark Snyder

University of Minnesota

Follow this and additional works at: https://digitalcommons.unl.edu/psychfacpub

Part of the Psychiatry and Psychology Commons

Vescio, Theresa K.; Gervais, Sarah J.; Heidenreich, Swen; and Snyder, Mark, "The Effects of Prejudice Level and Social Influence Strategy on Powerful People's Responding to Racial Out-Group Members" (2006). Faculty Publications, Department of Psychology. 370.

https://digitalcommons.unl.edu/psychfacpub/370

This Article is brought to you for free and open access by the Psychology, Department of at DigitalCommons@University of Nebraska - Lincoln. It has been accepted for inclusion in Faculty Publications, Department of Psychology by an authorized administrator of DigitalCommons@University of Nebraska - Lincoln. 
Published in European Journal of Social Psychology 36 (2006), pp. 435-450; doi 10.1002/ ejsp.344

Copyright ( 2006 John Wiley \& Sons, Ltd.Used by permission

http://www.interscience.wiley.com

Submitted June 30, 2004; accepted January 27, 2006.

\title{
The effects of prejudice level and social influence strategy on powerful people's responding to racial out-group members
}

\author{
Theresa K. Vescio, ${ }^{1}$ Sarah J. Gervais, ${ }^{1}$ Swen Heidenreich, ${ }^{2}$ and Mark Snyder ${ }^{3}$ \\ ${ }^{1}$ Pennsylvania State University, USA \\ ${ }^{2}$ Philipps-Universität Marburg, Germany \\ ${ }^{3}$ University of Minnesota, USA \\ Corresponding author - Theresa K. Vescio, Department of Psychology, \\ Penn State University, University Park, PA 16803, USA; email tkv1@psu.edu
}

\begin{abstract}
This research tested the hypothesis that the responding of high, but not low, prejudice White Americans would vary as a function of manipulations of powerful people's attention to subordinate strengths that facilitate goal strivings versus weaknesses that block goals. To examine this possibility, White participants were assigned to leader roles and an interaction with a low power Black "employee" was staged. Consistent with predictions, findings revealed that high prejudice White participants who were attentive to subordinate strengths and goal strivings versus subordinate weaknesses and blocked goals, evaluated and treated a Black employee more positively. The responding of low prejudice participants did not, however, vary as a function of attention to strengths and goal facilitation versus weaknesses and blocked goals. Findings suggest that stereotypes of the groups to which low power people belong influence powerful people's judgment and behavior when stereotypes are endorsed by powerful people and match powerful people's goals.
\end{abstract}

Consider the relationship between professors and students in a typical academic environment. Professors hold positions that confer power and legitimate the influence they have over students. Professors are expected to inspire scholarship, convey knowledge, and uphold academic standards. Achieving these goals requires attention to and judgments about the abilities of students along various critical dimensions (e.g., intellect, motivation). There are, however, at least two reasons to suspect that one's ability to evaluate students along traditionally valued academic dimensions may, at times, be tainted by the lens of cultural stereotypes. First, some social groups are stereotyped in ways that have implications for academic success. For instance, cultural stereotypes suggest that Black Americans possess attributes that should impede success in academic environments (e.g., unintelligent, un- 
motivated) and both high and low prejudice White Americans are aware of these stereotypes (e.g., Devine, 1989; Gaertner \& Dovidio, 1986).

Second, elevated power often is associated with stereotypic perceptions and discrimination. Generally speaking, social perceivers have been assumed to process information about others in the least effortful manner (e.g., category-based processing) unless sufficiently motivated to do otherwise (Brewer, 1988; Fiske \& Neuberg, 1990). In addition, as Fiske (1993) has noted, power is a factor that may influence whether one is motivated to go beyond categorical knowledge. In many situations, low power individuals are highly motivated to individuate and carefully process information about those who have control over them to increase subjective feelings of predictability and control. By contrast, high power people are often apt to perceive low power people in stereotypic terms either because they lack the cognitive resources to individuate their subordinates or because they are motivated to maintain power differentials (e.g., Goodwin, Gubin, Fiske, \& Yzerbyt, 2000; Rodriguez-Bailon, Moya, \& Yzerbyt, 2000). Consistent with these ideas, findings show that high power people pay more attention to stereotype-consistent information and less attention to stereotype-inconsistent information about others than do low power people (e.g., Goodwin et al., 2000). Category-based perception among high power people also leads to discrimination (e.g., Sachdev \& Bourhis, 1985, 1991) and may elicit stereotype-confirmation from the low power people who are the recipients of discrimination ( Vescio, Gervais, Snyder, \& Hoover, 2005; Vescio, Snyder, \& Butz, 2003; Word, Zanna, \& Cooper, 1974).

Stereotypic judgments and discriminatory actions are not, however, ubiquitous among the powerful. Theorists have noted that powerful peoples' tendencies to behave in stereotypic and discriminatory ways should vary as a function of both individual difference variables (e.g., dominance) and situational factors (e.g., interdependencies among the powerful and the powerless, Fiske, 1993). In fact, our recent work demonstrates that situational factors may either facilitate or impede powerful peoples' tendencies to behave in stereotypic and discriminatory ways toward their subordinates (Vescio et al., 2003, 2005). Interestingly, however, few contemporary theorists have adopted a person $\times$ situation approach in their attempts to study the links between power, stereotypes and discrimination in a single context. The present theorizing and research addresses this gap.

First, to consider the interactive influence of situation and person factors on powerful peoples' stereotype-based perceptions of and behaviors toward their subordinates, we review theorizing and research on social influence strategy $\times$ stereotype match effects (Vescio et al., 2003, 2005). As noted, findings from this research point to situational factors that facilitate and discourage the stereotypic perceptions and discriminatory acts of powerful people. We then integrate considerations of prior work on power with contemporary theorizing and research on racial prejudice, which point to differences in the cognitive representations of high and low prejudice Whites. This integration leads to predictions regarding when powerful Whites who are high in prejudice and powerful Whites who are low in prejudice will exhibit race biases in judgments about and behavior toward low power Blacks.

\section{Social Influence Strategy and Stereotype Match}

To understand how situational factors influence powerful people's tendency to exhibit stereotype consistent biases in judgments and behaviors toward their subordinates, features of powerful positions must be considered. First, positions of power are associated with particular goals. Second, the goals of high power positions are typically internalized by the people who hold the high power positions. Finally, the contributions of low power people are required if the goals associated with positions of power are to be achieved. In fact, there would be no subordinates over whom people were given power if the activities and contributions of subordinates were not necessary for goal attainment. 
For instance, a coach is hired to produce a winning season and the coach wants to win and to win the coach must inspire winning performances from his/her team members.

Given the features of high power positions, Vescio et al. (2003) suggested that powerful people interact with subordinates on the basis of their beliefs about how subordinates' strengths and weaknesses are linked to goal-strivings. These beliefs serve as schemas that guide attention and influence behavior. As a result, we refer to these beliefs as social influence strategies.

Importantly, social influence strategies can be manipulated across situations and take one of two forms. Weakness-focused social influence strategies are based on beliefs about how subordinates may impede goal strivings. As such, they are beliefs that link subordinates' shortcomings to failure on critical tasks and blocked goals. Therefore, weakness-focused social influence strategies are associated with heightened attention to contextually relevant weaknesses in subordinates and efforts to avoid subordinate-related impediments to goal strivings. In contrast, strength-focused social influence strategies are beliefs about how subordinates may enhance goal strivings. As a result, they are beliefs that link subordinates' strengths to success on critical tasks and the facilitation of goal strivings. Therefore, strength-focused social influence strategies are associated with heightened attention to the contextually relevant strengths in subordinates and efforts to enhance subordinate-related goal strivings.

Considering the distinction between strength-focused and weakness-focused social influence strategies, Vescio et al. (2003) introduced the social influence strategy $\times$ stereotype match hypothesis. This hypothesis predicts that powerful people will exhibit stereotypic biases in judgments about and behavior toward low power people if the cultural stereotypes of the groups to which low power people belong are both contextually relevant and match adopted social influence strategies. More specifically, if situations encourage weakness-focused social influence strategies, then powerful people should initiate interactions with subordinates with a focus on those weaknesses that may impede goal strivings. In masculine domains, for instance, the attributes required for success (e.g., strategic, competitive, influential) are stereotypically associated with men, but not women. Thus, the cultural stereotypes of women match and inform weakness-focused social influence strategies. Stereotypes provide information about the relevant dimensions along which female subordinates may have shortcomings (e.g., illogical, weak) that may impede goal strivings and lead to anti-female biases in judgment and behavior.

In contrast, if situations encourage strength-focused social influence strategies, then powerful people should initiate interactions with a focus on those strengths in subordinates that may enhance goal strivings. Continuing the example of a masculine context, there is a mismatch between social influence strategy and the content of the cultural stereotype of women. In this case, stereotypes describing the strengths of women (e.g., nurturing, caring) are contextually irrelevant. Reliance on stereotypes in this situation would not provide information that would facilitate goal achievement. Therefore, stereotype-based biases should not ensue.

Together, the foregoing considerations suggest that a social influence strategy $\times$ stereotype match effect should emerge when stereotypes describe the contextually relevant shortcomings of low power people (as do stereotypes of women in traditionally masculine domains). Consistent with this suggestion, findings show that powerful men who are weakness-focused (vs. strength-focused) exhibit stronger anti-female biases in task assignment (Vescio et al., 2003) and behave in patronizing ways toward low power women (Vescio et al., 2005).

\section{Racial Prejudice and Stereotype Match Effects}

The initial theorizing and research on stereotype match effects derived from a consideration of gender biases in traditionally masculine domains (Vescio et al., 2003, 2005). The theoretical statements 
were, however, considered to be broad statements about the influences of cultural stereotypes on powerful peoples' judgments about and behaviors toward their subordinates, as opposed to genderspecific effects. As a result, stereotype match effects should describe racial biases in powerful Whites' judgments about and behaviors toward low power Blacks, as well as gender biases in powerful men's judgments and behaviors.

As noted in the introductory example, cultural stereotypes imply that Black Americans possess shortcomings that may impede academic success (e.g., unintelligent, unmotivated). In academic domains, the cultural stereotypes of Black Americans should then match and inform the weakness-focused social influence strategies of powerful Whites. More specifically, if powerful Whites adopt weakness-focused social influence strategies then they should initiate interactions with subordinates given attention to those weaknesses that may impede goal strivings. In an academic domain, the attributes required for success are stereotypically associated with Whites, but not Blacks. Therefore, the cultural stereotypes of Blacks match and inform weakness-focused social influence strategies, providing contextually relevant information about the dimensions along which Black subordinates may have goal-related shortcomings.

In contrast, if situations encourage strength-focused social influence strategies, then powerful people should focus on those strengths in subordinates that may enhance goal strivings. Continuing with the example of an academic context, there is a mismatch between social influence strategies and the content of the cultural stereotypes of Blacks. In this case, stereotypes of Blacks point to strengths that are contextually irrelevant (e.g., athletic, musical). Because reliance on stereotypes would not provide information about how subordinates may enhance goal strivings, stereotype-based biases in judgments and behaviors should not emerge.

Together, the foregoing considerations lead to the prediction that, in an academic context, powerful Whites will exhibit anti-Black biases in judgment and behavior when situations encourage weaknessfocused (but not strength-focused) social influence strategies. There are, however, prior findings that introduce the possibility that high and low prejudice Whites may differ in their susceptibility to social influence strategy $\times$ stereotype match effects.

In prior research, powerful men exhibited social influence strategy $\times$ stereotype match effects, whereas powerful women did not (Vescio et al., 2003, 2005). Such gender differences had been predicted based on findings showing that men are more likely than women to endorse both hostile and benevolent sexist beliefs (Glick \& Fiske, 2001), view women as less agentic (Diekman \& Eagly, 2000; Spence \& Buckner, 2000) and hold less varied and less complex representations of women (see Park \& Judd, 1990). Thus, it was reasoned that cultural stereotypes would be influential only to the degree that they are endorsed and cognitively internalized (see Vescio et al., 2003). In addition, because women reject negative cultural stereotypes of women more strongly then do men, powerful women should be less likely then powerful men to bring stereotypes to bear on judgments about women and exhibit antifemale biases toward their subordinates. Although our prior findings were consistent with this notion, target gender and leader gender were confounded. As a result, in-group favoritism, regardless of stereotype endorsement and internalization, could have produced gender differences in social influence strategy $\times$ stereotype match effects.

However, if the endorsement and internalization of cultural stereotypes is a precondition of stereotype match effects, then powerful Whites who are high and low in prejudice may differ in the degree that they exhibit social influence strategy $\times$ stereotype match effects. This is because high prejudice Whites and low prejudice Whites differ in the degree to which they endorse and have internalized the negative cultural stereotypes of Blacks. For instance, contemporary theories of racial prejudice postulate that low prejudice people have egalitarian or non-prejudiced self-images that are activated in race-relevant contexts and that result in pro-Black or non-biased responding (e.g., Biernat, Vescio, \& Theno, 1996; Devine, 1989; Gaertner \& Dovidio, 1986; Plant \& Devine, 1998). Findings also suggest 
that there are differences in the content of the stereotypic representations of high and low prejudice Whites. For example, findings show that dispositional traits associated with the cultural stereotype are activated automatically when the category "Black" is primed and perceivers are high prejudice Whites, but not low prejudice Whites (Lepore \& Brown, 1997). Additionally, stereotypes of both high and low prejudice Whites contain information about the relative lower social status of Black Americans (e.g., poor), but only the stereotypes of high prejudice Whites contain stereotypic, dispositional trait information (Vescio \& Biernat, 1999; Wittenbrink \& Henly, 1996). If low prejudice Whites are motivated toward non-biased responding and have not internalized the trait information associated with the cultural stereotypes of Blacks, then the cultural stereotypes should not influence their judgments about or behaviors toward their Black subordinates.

Together, the foregoing considerations lead to the prediction that powerful Whites who are high in prejudice should exhibit social influence strategy $\times$ stereotype match effects, whereas powerful Whites who are low in prejudice should not. More specifically, high prejudice Whites should exhibit stronger anti-Black bias in their judgments about and behaviors toward low power Blacks when they are weakness-focused then strength-focused. The responding of low prejudice Whites should not, however, vary as a function of social influence strategy.

\section{Method}

\section{Participants}

Students enrolled in an introductory psychology course at the Pennsylvania State University completed the Modern Racism Scale (McConahay, Hardee, \& Batts, 1981) at the outset of the semester. Modern Racism scores could potentially range from 7 to 35. Scores of the White students ranged from 7 to $30(M=15, \alpha=0.86)$. A tertile split was performed to identify potential participants who were high prejudice (scores $>18$ ) and low prejudice (scores $<11$ ).

Within gender and prejudice level, 64 White participants were randomly selected, recruited by phone, and randomly assigned to social influence strategy condition (strength or weakness-focused). One woman repeatedly failed to arrive for scheduled sessions. The responses of two other women, who expressed suspicion during debriefing, were omitted from analyses. This left a working data set $(N=61)$ comprised of the responses of 28 men (7 per condition) and 33 women ( 9 in the low prejudice, strength-focused condition and 8 in every other condition).

\section{Procedure}

The procedure was similar to that used by Vescio et al. (2003, Study 1). After signing a consent statement, participants were told that they would be participating in an investigation of leadership styles and productivity. More specifically, participants were led to believe that each experimental session involved two students - themselves and another Penn State student, who was working down the hall (and from whom they were separated for purposes of experimental control). Participants were then told that one person would be assigned to the role of team leader and the other person would be the employee. In reality, there was no experimental partner and interactions among leaders and employees were staged.

Participants completed a leadership questionnaire and a background questionnaire (i.e., demographic information, general likes and dislikes). After the staged scoring of two completed leadership 
questionnaires, participants were assigned the leader role and told that they would evaluate, assign tasks to, and supervise the work of the employee participant down the hall. To increase the believability that there was a participant working in a nearby room and to provide a means of conveying target race, each participant posed for a Polaroid photograph. Participants were told that photographs and completed background questionnaires would be exchanged between leader and employee participants to facilitate getting acquainted. Participants then saw a photograph of a Black employee, who was the same gender as the participant, and a background questionnaire that appeared to have been completed by the employee participant.

The experimental task was then described. Participants were told that they would supervise a school renovation project that involved a series of administrative and strategic planning tasks (e.g., curriculum planning and blue print selection). The administrative and strategic planning tasks were presented as the primary determinants of the quality of the project (i.e., valued tasks) and described as requiring attributes associated with academic success (e.g., logical and mathematical). Other tasks were also involved in the school renovation project (e.g., community mobilization and diversity inclusive interior design tasks). However, instructions indicated that the successful completion of the community mobilization and design tasks, while making the school "look good" and "feel good" to the diverse urban community served, would not contribute to the educational quality of the project (i.e., devalued tasks). These devalued tasks were described as requiring attributes that are stereotypically associated with Black Americans (e.g., communal and streetwise), as indicated by pilot-testing.

To reinforce the differential value of the tasks, participants were told that each employee would receive (a) 10 points for each successfully completed administrative/ strategic planning, (b) 5 points for each successfully completed community mobilization/design task, and (c) \$30.00 if they earned 25 points based on their completion of the three tasks assigned to them. In other words, employees would only have the potential to earn money if more than half of the problems assigned to them were valued tasks. Participants were told that they would not complete problems, but that leaders who exhibited strong decision-making and managerial skills (as evaluated by faculty in the school of business) would earn $\$ 50.00$.

Leadership instructions were then provided. Social influence strategies were manipulated within the context of these instructions (for details see Vescio et al., 2003, 2005). In the strength-focused condition the best leaders were described as those who were skilled in their ability to identify the strengths of others and maximize the likelihood that valued tasks are completed by those possessing the requisite skills. By contrast, in the weakness-focused condition the best leaders were described as those who were skilled in their ability to identify the weaknesses and limitations of others and who minimize the likelihood that valued tasks are completed by those lacking the requisite skills.

Similar to Vescio et al. (2003, Study 1), a two-phase staged interaction then ensued. During the getting acquainted phase, participants selected interview questions to ask and skills tests to assign to the employee. Participants then considered the information they received during the getting acquainted phase and, during final decision phase, participants evaluated and assigned final tasks to the employee. All interactions involved written exchanges.

\section{Dependent Variables}

Interview Questions

After reading the leadership instructions, participants were given a list of 16 interview questions. Each question was leading in that it requested a description of a stereotypically White or Black 
strength or weakness, which mapped onto the attributes used to describe the valued or devalued tasks, respectively. Participants chose four interview questions to ask the employee. For each participant, we summed the number of questions selected that elicited evidence of (1) strengths on valued tasks (e.g., Tell me about a time when you were proud of your logic skills,) (2) weaknesses on valued tasks (e.g., Tell me about a time when you felt irrational or overly emotional), (3) strengths on devalued tasks (e.g., Tell me about a time when you put the needs of your community or family before your own needs), or (4) weaknesses on devalued tasks (e.g., Tell me about a time when you had to do what was best for yourself regardless of the consequences your actions had for others).

\section{Skills Test}

While the employee was presumably writing responses to the interview questions, participants looked over a set of skills tests. These tests tapped skills related to the valued tasks or skills related to the devalued tasks. Tests were constructed from logic and quantitative GRE problems and pilot-tested to assure they were perceived to be difficult. The same problems appeared in the administrative/strategic planning and the community mobilization/design problem sets, but contexts were altered to mask this fact. Each problem appeared on an individual page, followed by supporting informationtutorial and helpful hints. Participants selected four problems and indicated whether each would be given to the employee with or without supporting information.

We created a variable to reflect the proportion of valued skills tests assigned, or a variable that reflects the proportion of skills tests that assessed skills related to the valued task (i.e., number of valued skills tests assigned/total assigned). We also created skills test support variables by considering the number of (1) valued skills tests given with support minus the number of valued skills tests given without support (or with no help) and (2) devalued skills tests given with support minus the number of devalued skills tests given without support.

\section{Final Task Assignment}

After looking over the employee's responses to the interview questions and solutions to the skills tests, ${ }^{1}$ participants were presented with valued administrative/strategic planning tasks and devalued community mobilization/design tasks. Participants assigned five problems to the employee. The final task assignment variable reflected the proportion of final tasks assigned that were valued (i.e., provide a chance to earn the most money).

\section{Employee Appraisals}

While employees were presumably working on the tasks, participants completed a brief employee evaluation form. Participants first evaluated the employee along 8 dimensions, using 9-point scales (endpoints labeled "Not At All Skilled" and "Extremely Skilled"). These included three skill sets related to the valued tasks (i.e., logic and reasoning, geometry, and algebra) and ratings of general ad-

1 Participants were always provided with confirmatory evidence. Responses to the interview questions always provided descriptions of the skills or shortcomings requested by the leader. Participants were also provided with responses to the skills tests that corresponded to the amount of help given. If participants provided support along with the skills tests, they saw a solution that was more than $70 \%$ accurately completed with three or fewer scratched out and recomputed portions. If no help was provided, however, participants were presented with a solution to the problem that was less than $30 \%$ complete with six scratched out and recomputed sections. 
ministrative and strategic planning skills. We averaged across these four ratings to create a valued skill appraisal variable $(\alpha=0.93)$. Participants also rated the employee on skills of importance to the devalued tasks (e.g., urban relations, budgeting, and ethnic creativity) and general community mobilization/ethnic design skills. We averaged across these four ratings to create a devalued skill appraisal variable $(\alpha=0.89)$.

\section{Estimated Employee Success}

At the end of the employee evaluation form, participants reported perceptions of the likelihood of three kinds of employee success. Participants rated the likelihood that the employee would successfully complete the assigned tasks, earn enough points to receive a monetary reward, and be promoted to a leadership role in a follow-up study. Ratings were made on 9-point scales (endpoints "Extremely Unlikely" and "Extremely Likely"). We averaged across ratings to create an index of estimated employee success $(\alpha=0.89)$.

\section{Results}

We predicted that the responding of high prejudice participants, but not low prejudice participants, would vary as a function of social influence strategy. High prejudice participants who were strengthfocused (vs. weakness-focused) were expected to: (1) ask more interview questions that elicit evidence of strengths on valued tasks, (2) assign more valued skills tests and provide greater support with those tests, (3) evaluate the employee more favorably, (4) assign more valued tasks, and (5) estimate greater employee success. The responding of low prejudice participants was not, however, expected to vary as a function of social influence strategy.

\section{Interview Questions}

Interview questions were submitted to a mixed model ANOVA. Question relevance (valued or devalued tasks) and question valence (employee strengths or weaknesses) were within-participants variables in this analysis. Social influence strategy, participant prejudice, and participant gender were between-participants variables. A main effect of question valence emerged, $F(1,53)=65.14, p<0.0001$, $\eta_{\mathrm{p}}^{2}=0.53$, revealed that participants asked more questions that elicited evidence of the employee's strengths $(M=2.97)$ than weaknesses $(M=1.03)$.

The main effect of question valence was, however, qualified by a question valence $\times$ participant prejudice interaction, $F(1,53)=6.54, p<0.02, \eta_{\mathrm{p}}^{2}=0.10$ (see Table 1). Simple effects tests were performed to examine the effects of social influence strategy within prejudice level. These analyses re-

Table 1. The effects of question valence and prejudice level on interview question selection

\begin{tabular}{lcc}
\hline \multirow{2}{*}{$\begin{array}{l}\text { White Participants' } \\
\text { prejudice level }\end{array}$} & \begin{tabular}{c} 
Valence of question \\
\cline { 2 - 3 }
\end{tabular} & $\begin{array}{c}\text { Evidence of employee's } \\
\text { strengths sought }\end{array}$ \\
High & $2.67^{\mathrm{a}}$ & $1.33^{\mathrm{b}}$ \\
Low & $3.26^{\mathrm{c}}$ & $0.74^{\mathrm{d}}$ \\
\hline
\end{tabular}

Adjacent means with different superscripts differ significantly, $p<0.05$. 
vealed that both high prejudice and low prejudice participants asked more questions that elicited evidence of the employee's strengths than weaknesses. This effect was, however, stronger among low prejudice participants, $F(1,30)=65.61, p<0.0001, \eta_{\mathrm{p}}^{2}=0.61$, than high prejudice participants, $F(1,28)$ $=13.49, p<0.002, \eta_{\mathrm{p}}^{2}=0.32$. Additionally, the two contrasts that compared the magnitude of the prejudice effect within question valence were both significant. Low prejudice participants, compared to high prejudice participants, asked more questions that elicited evidence of the employee's strengths, $F(1,53)=6.51, p<0.02, \eta_{\mathrm{p}}^{2}=0.11$, and fewer questions that elicited evidence of the employee's weaknesses, $F(1,53)=6.45, p<0.02, \eta_{\mathrm{p}}^{2}=0.11$.

\section{Skills Tests}

\section{Proportion of Valued Skills Tests Assigned}

The proportion of valued skills tests assigned was submitted to a social influence strategy $\times$ participant prejudice $\times$ participant gender between-participants ANOVA. A main effect of prejudice, $F(1$, 53) $=4.49, p<0.04, \eta_{\mathrm{p}}^{2}=0.08$, revealed that high prejudice participants $(M=0.50)$ assigned fewer valued skills tests to the employee then did low prejudice participants $(M=0.63)$. The predicted social influence strategy $\times$ participant prejudice interaction was also significant, $F(1,53)=4.07, p<0.05, \eta_{\mathrm{p}}^{2}$ $=0.07$. As the top panel of Table 2 shows, high prejudice participants assigned fewer valued tasks to the employee when they were weakness-focused than strength-focused, $F(1,53)=5.54, p<0.03, \eta_{\mathrm{p}}^{2}=$ 0.09. The skills tests assigned by low prejudice participants did not, however, vary as a function of social influence strategy, $F<1$. Additionally, high prejudice, compared to low prejudice, participants assigned fewer valued tasks to the employee in the weakness-focused conditions, $F(1,53)=8.43, p<$ $0.006, \eta_{\mathrm{p}}^{2}=0.14$, but not in the strength-focused conditions, $F<1$.

Table 2. The effects of participant prejudice level and social influence strategy on skills test assignment and support, employee appraisals, final task assignment, and estimated success

\begin{tabular}{|c|c|c|c|c|}
\hline & \multicolumn{4}{|c|}{ White participants' prejudice level } \\
\hline & \multicolumn{2}{|c|}{$\begin{array}{c}\text { High } \\
\text { Social influence strategy }\end{array}$} & \multicolumn{2}{|c|}{$\begin{array}{c}\text { Low } \\
\text { Social influence strategy }\end{array}$} \\
\hline & Strength-focused & Weakness-focused & Strength-focused & Weakness-focused \\
\hline $\begin{array}{l}\text { Proportion valued skills } \\
\text { tests assigned }\end{array}$ & $0.61^{\mathrm{a}}$ & $0.40^{\mathrm{b}}$ & $0.62^{a}$ & $0.65^{\mathrm{a}}$ \\
\hline \multicolumn{5}{|l|}{$\begin{array}{l}\text { Skills test support } \\
\text { (\# with vs. without support) }\end{array}$} \\
\hline Valued & $2.13^{\mathrm{a}}$ & $0.67^{\mathrm{b}}$ & $1.75^{\mathrm{a}}$ & $1.80^{\mathrm{a}}$ \\
\hline Devalued & $1.53^{\mathrm{a}}$ & $1.93^{\mathrm{b}}$ & $1.25^{\mathrm{a}}$ & $1.33^{\mathrm{a}}$ \\
\hline \multicolumn{5}{|l|}{ Employee appraisals } \\
\hline Valued & $7.27^{\mathrm{a}}$ & $6.22^{\mathrm{b}}$ & $7.12^{\mathrm{a}}$ & $7.03^{a}$ \\
\hline Devalued & $6.93^{\mathrm{a}}$ & $6.89^{\mathrm{a}}$ & $6.69^{\mathrm{a}}$ & $6.90^{\mathrm{a}}$ \\
\hline $\begin{array}{r}\text { Final task assignment } \\
\text { (proportion valued) }\end{array}$ & $0.45^{\mathrm{a}}$ & $0.24^{\mathrm{b}}$ & $0.55^{\mathrm{a}}$ & $0.56^{\mathrm{a}}$ \\
\hline Estimates of employee success & $7.58^{\mathrm{a}}$ & $6.07^{\mathrm{b}}$ & $7.63^{\mathrm{a}}$ & $7.53^{\mathrm{a}}$ \\
\hline
\end{tabular}

For each dependent variable, means with different superscripts differ significantly, $p<0.05$. 


\section{Skills Test Support}

The skills test support variables were submitted to a mixed model ANOVA. Type of task support (valued or devalued) was a within-participants variable in this analysis. Social influence strategy, participant prejudice, and participant gender were between-participants factors. The only single significant effect to emerge from this analysis was the predicted type of task support $\times$ social influence strategy $\times$ participant prejudice interaction, $F(1,53)=4.71, p<0.04, \eta_{\mathrm{p}}^{2}=0.08$. The means for this interaction are in the second panel of Table 2.

To interpret the three-way interaction we first examined the magnitude of the social influence strategy $\times$ participant prejudice interaction on each variable (valued and devalued). The social influence strategy $\times$ participant prejudice level interaction was significant on valued skills test support, $F(1,53)$ $=6.37, p<0.02, \eta_{\mathrm{p}}^{2}=0.11$, but not devalued skills test support, $F<1$. On valued skills test support, high prejudice participants provided the employee with more support when strength-focused than weakness-focused, $F(1,53)=6.37, p<0.002, \eta_{\mathrm{p}}^{2}=0.17$. Among low prejudice participants, however, the support offered with valued task assignments did not vary as a function of social influence strategy, $F<$ 1. Additionally, in the weakness-focused conditions, high prejudice participants offered less support than did low prejudice participants, $F(1,53)=6.48, p<0.02, \eta_{p}^{2}=0.11$, but in the strength-focused conditions the support provided by high and low prejudice participants did not differ, $F<1.05, p>0.31$.

In sum, the analyses of the skills test variables paint an interesting picture. High prejudice participants who were weakness-focused assigned fewer valued skills tests to their employee and provided less support for those tests then did high prejudice participants who were strength-focused or low prejudice participants (both strength and weakness focused).

\section{Employee Appraisals}

Employee appraisals were submitted to a mixed model ANOVA. Type of skill appraised (valued or devalued) was a within-participants variable in this analysis. Social influence strategy, participant prejudice, and participant gender were between-participant variables. The predicted interaction among type of skill appraised, social influence strategy, and participant prejudice was not significant, $F(1,53)=2.36, p<0.13, \eta_{\mathrm{p}}^{2}=0.04$. As show in the third panel of Table 2, however, the means were in the expected direction and the social influence strategy $\times$ participant prejudice interaction was significant on valued skill appraisals, $F(1,53)=4.75, p<0.04, \eta_{\mathrm{p}}^{2}=0.08$, but not on devalued skill appraisals, $F<1, p>0.50$. On valued skill appraisals, social influence strategies affected the responding of high prejudice participants, $F(1,53)=6.49, p<0.02, \eta_{\mathrm{p}}^{2}=.11$; weakness-focused participants more negatively appraised the employee than did strength-focused participants. By contrast, the valued skill appraisals of low prejudice people were similar across social influence strategy conditions, $F\langle 1, p\rangle$ 0.51 . Additionally, in the weakness-focused conditions, high prejudice participants evaluated the employee more negatively than did low prejudice participants, $F(1,53)=4.75, p<0.04, \eta_{\mathrm{p}}^{2}=0.08$. However, high and low prejudice participants in the strength-focused conditions similarly evaluated the employee, $F<1, p>0.77$.

\section{Final Task Assignment}

The final task assignment variable was submitted to a social influence strategy $\times$ participant prejudice $\times$ participant gender between-participants ANOVA. A main effect of participant prejudice, $F(1$, $53)=12.61, p<0.001, \eta_{\mathrm{p}}^{2}=0.19$, revealed that low prejudice participants $(\mathrm{M}=0.55)$ assigned more valued tasks to the employee than did high prejudice participants $(\mathrm{M}=0.35)$. The predicted prejudice $\times$ social influence strategy interaction was also significant, $F(1,53)=4.25, p<0.05, \eta_{\mathrm{p}}^{2}=0.07$. As shown 
in the second to the last panel of Table 2, among high prejudice participants, strength-focused participants assigned more valued tasks to the employee than did weakness-focused participants, $F(1$, $53)=4.25, p<0.05, \eta_{\mathrm{p}}^{2}=0.11$. This effect did not, however, emerge among low prejudice people, $F$ $<1$. Finally, in the weakness-focused conditions, high prejudice participants assigned fewer valued tasks to the employee than did low prejudice participants, $F(1,53)=14.78, p<0.001, \eta_{\mathrm{p}}^{2}=0.22$. In the strength-focused conditions, however, high and low prejudice participants made similar final task assignments, $F<1$.

\section{Estimates of Success}

Estimates of success were submitted to a social influence strategy $\times$ participant prejudice $\times$ participant gender between-participants ANOVA. This analysis revealed main effects of social influence strategy, $F(1,53)=6.35, p<0.03, \eta_{\mathrm{p}}^{2}=0.11$, and participant prejudice, $F(1,53)=5.36, p<0.03, \eta_{\mathrm{p}}^{2}=0.09$. Estimates of employee success were greater in the strength-focused condition then the weakness-focused condition (Ms $=7.60$ and 6.80, respectively) and among low prejudice participants then high prejudice participants (Ms $=7.58$ and 6.38 , respectively). More importantly, these effects were qualified by the predicted prejudice level $\times$ social influence strategy interaction, $F(1,53)=5.75, p<0.03, \eta_{p}^{2}$ $=0.10$ (see the bottom panel of Table 2). Among high prejudice participants, those who were weakness-focused estimated less employee success than did those who were strength-focused, $F(1,53)=$ $11.94, p<0.002, \eta_{\mathrm{p}}^{2}=0.19$. Among low prejudice participants, estimates of success did not vary across social influence strategy conditions, $F<1$. Contrasts were also performed to compare the responding of high and low prejudice participants in each social influence strategy condition. High prejudice participants estimated less success from the employee than did low prejudice participants in the weakness-focused conditions, $F(1,53)=10.96, p<0.002, \eta_{\mathrm{p}}^{2}=0.17$, but did not differ in the strength-focused conditions, $F<1$.

\section{Exploratory Analyses}

Stereotype-consistent perceptions and evaluations are typically documented by way of comparisons across targets of different races (e.g., White versus Black). In the absence of that explicit comparison, the possibility remains that weakness-focused participants respond more negatively than do strength-focused participants toward all low power people (e.g., White and Black). We find this possibility unlikely given the specificity of the social influence strategy $\times$ stereotype match effects. However, to more directly examine this issue we recruited 31 additional high prejudice participants, randomly assigned them to social influence strategy conditions and ran them through the same experimental procedures with two changes. First, rather than being presented with a Black employee, participants were presented with a White employee. Second, we omitted the interview question variable, since no social influence strategy $\times$ participant prejudice effects emerged on that variable.

We found that high prejudice Whites responded similarly to the White subordinate in the strengthfocused (SF) and the weakness-focused (WF) conditions, and this was true across variables, including: (1) proportion of valued skills tests assigned $(M s \mathrm{SF}=0.57$ and $\mathrm{WF}=0.55)$, (2) evaluations $(M \mathrm{SF}=$ 7.17 and $\mathrm{WF}=7.42)$, (3) final task assignments $(\mathrm{Ms} S \mathrm{SF}=0.46$ and $\mathrm{WF}=0.53)$, and (4) estimated success $(M s \mathrm{SF}=7.27$ and $\mathrm{WF}=7.40)$, all $F \mathrm{~s}<1$. Additionally, comparing the responding of high prejudice participants in the weakness-focused condition as a function of employee race revealed consistent differences in the predicted direction, all $F \mathrm{~s}(1,30)>4.20, p s<0.05$. High prejudice Whites in the weakness-focused condition responded more negatively to the Black subordinate than to the White subordinate on all measures. 
Table 3. Correlations among dependent variables

\begin{tabular}{lccccc}
\hline & $\begin{array}{c}\text { Skills } \\
\text { tests }\end{array}$ & $\begin{array}{c}\text { Skills test } \\
\text { support }\end{array}$ & $\begin{array}{c}\text { Valued } \\
\text { appraisals }\end{array}$ & $\begin{array}{c}\text { Final task } \\
\text { assignment }\end{array}$ & $\begin{array}{c}\text { Estimated } \\
\text { success }\end{array}$ \\
\hline Positive IQ & 0.25 & -0.15 & 0.24 & $0.26^{*}$ & 0.23 \\
Skills tests & & $0.29^{*}$ & 0.13 & 0.14 & 0.09 \\
Skills test support & & $0.36^{*}$ & $0.35^{*}$ & $0.31^{*}$ \\
Valued appraisals & & & $0.51^{*}$ & $0.51^{*}$ \\
Final task assignment & & & $0.59^{*}$ & \\
\hline
\end{tabular}

Positive IQ = positive interview questions. Significant correlations are denoted by an asterisk, $p<0.05$.

Next, considering the responses of all participants who responded to a Black employee in the primary study, we estimated correlations among the dependent variables along which significant effects emerged. These included the following six variables: the number interview questions asked eliciting strengths, the proportion of valued skills tests assigned the employee, the number of valued skills tests assigned with support, valued employee appraisals, the proportion of valued final task assignments, and estimated success. The correlations among variables are presented in Table 3.

Two noteworthy patterns emerged in the correlation matrix. First, variables measured at the same time were correlated. The number of skills tests assigned and the support provided with those skills tests were positively associated. Employee appraisals, final task assignments, and estimated success, which were measured together at the conclusion of the experiment, were also highly and positively associated. Second, skills test support was positively associated with each of the subsequently measured variables - valued appraisals, final task assignments, and estimates of success. This introduces the possibility that the support that high prejudice participants provided to the Black employee mediated the relation between social influence strategy and the final variables (appraisals, final task assignments, and estimated success).

To examine this possibility, we considered the responding of high prejudice participants (contrast coded: strength-focused $=1$ and weakness-focused $=-1$ ), which drove the significant social influence strategy effects documented above, and conducted mediation analyses (Baron \& Kenny, 1986). We know from the results reported above that social influence strategies accounted for significant variance in valued skills tests support (the potential mediator) and each subsequently measured variable (valued appraisals, final task assignments, and success estimates). Therefore, we simultaneously considered social influence strategies and skills test support as predictors of each of the final outcome measures. There were neither (a) reductions in the association between social influence strategies and the dependent variables when the effects of skills test support were controlled (all relations remained highly significant) nor (a) significant relations that remained among skills test support and the subsequently measured variables when the effect of social influence strategy was controlled, all $t$ s $<1.22$, ps $>0.23$. In other words, there was no evidence that skills test support mediated the relation between social influence strategies and the final variables measured that emerged among high prejudice participants.

\section{Discussion}

The results of this research revealed social influence strategy $\times$ stereotype match effects across diverse and varied dependent measures. As predicted, social influence strategies impacted the respond- 
ing of high prejudice Whites, but not low prejudice Whites. High prejudice Whites who were weakness-focused responded more negatively to the Black employee than did high prejudice Whites who were strength-focused or low prejudice Whites (strength and weakness-focused). High prejudice participants who were weakness-focused gave the Black employee fewer opportunities to exhibit contextually valued strengths (e.g., assigned few valued tasks and provided little support with those tasks). They also gave the Black employee more negative evaluations, and fewer chances for earning monetary rewards (e.g., assigned fewer valued final tasks). These effects emerged on all variables except one-interview questions.

Exploratory analyses suggest that the social influence strategy effects found among high prejudice participants were due to racial biases, rather than being a result of the application of harsh standards to all employees. High prejudice participants' responses to the White employee did not vary as a function of social influence strategy. However, high prejudice participants who were weakness-focused responded more negatively when the employee was Black than White.

Together, the current findings point to the ways in which person and situation characteristics can interact to influence the degree to which powerful people behave in stereotype-based ways toward low power others who belong to negatively stereotyped groups. Most intriguingly, the present findings also point to simple situational manipulations that influence the orientation powerful people adopt toward their subordinates, such that biases in responding can be eliminated even among high prejudice Whites.

Interestingly, many contemporary theories of racial prejudice suggest that the responding of low prejudice people (whether they be aversive racists, ambivalent racists, or modern racists) is highly influenced by situational cues (e.g., Devine, 1989; Gaertner \& Dovidio, 1986; Katz, Glass, \& Cohen, 1973; Katz \& Hass, 1988; McConahay \& Hough, 1976; Sears, 1988; Sears \& Kinder, 1971). This is because unacknowledged negative attitudes toward Blacks persist among low prejudice Whites. As a result, low prejudice Whites may exhibit anti-Black biases in judgment and behavior when such biases slip by undetected (e.g., can be attributed to a non-racist justification, Gaertner \& Dovidio, 1986). However, in the present research, we found no evidence that the responding of low prejudice participants varied across situations. Even when low prejudice Whites were given license to behave in stereotypically negative ways (or weakness-focused) they did not exhibit more negative evaluations of and behaviors toward the Black employee. Instead, it was the responding of high prejudice Whites that varied as a function of the situational manipulation of social influence strategies.

It is possible that the race relevance of the present domain triggered monitoring processes among low prejudice people. Race may have been immediately salient at the onset of the experiment, arousing motives to respond without prejudice among low prejudice Whites (Plant \& Devine, 1998, 2003). This is a reasonable possibility. If motives curtailed biases in the responding of low prejudice Whites, then low prejudice Whites may be skilled in their monitoring and control abilities, even in cognitively taxing situations. This would suggest that highlighting the relevance of race to a context may sufficiently alert low prejudice Whites to a problem that requires correction. In contrast, the stereotyping of high prejudice Whites may be averted by altering perceptions of the link between one's subordinates and one's goals.

Above and beyond the individual difference findings reported, the current work points to how characteristics of both the individual and the situation can interact to produce social influence strategy $\times$ stereotype match effects. Person $\times$ situation considerations of phenomenon have consistently been characteristic of social psychological theorizing and research. However, such approaches have rarely been applied to considerations of the links between power, stereotypes, and discrimination. Instead, many models of power and stereotyping (e.g., Fiske, 1993; Jost \& Banaji, 1994) derive from the assumption that social perceivers tend to process information about others in relatively effortless and category-based ways unless they are sufficiently motivated to do otherwise. Elaborating this assumption to situations of power differentials has led to the suggestion that low power people are typically motivated to go beyond categorical knowledge to understand those who have power over them and 
acquire a sense of control (Fiske, 1993). In contrast, high power people presumably stereotype low power others either because they lack the motivation and/or ability to individuate or because they are motivated to maintain power differentials (Goodwin et al., 2000).

This treatment of the links between power and stereotypes may not, however, thoroughly consider the motives of the powerful in their dealings with the relatively powerless. In fact, the present findings suggest that the links between power and cultural stereotypes are more complex and nuanced than has previously been understood. In other words, it does not seem that stereotype-based judgments and behaviors of powerful people can be completely understood as an intrapersonal (inside the head) phenomenon. Instead, stereotype-based judgments and behaviors occur when cultural stereotypes fit with and serve the goals of powerful people in specific situations (see Fiske, 2004; Vescio et al., 2003). To better understand these processes, future research would benefit from considerations of both individual differences that ready people for stereotype-based judgments and behaviors and situation factors that make those judgments and behaviors seem appropriate given the ways in which powerful people choose to or are encouraged to strive toward their goals.

Future research should also consider the nuanced and complex patterns of behaviors that follow from stereotype-based judgments. For instance, recent work from our lab (Vescio et al., 2005) suggests that category-based judgments can result in both negative and seemingly positive behaviors towards subordinates from negatively stereotyped groups. Rather than acting in uniformly hostile and negative ways towards women, we found that male leaders who adopted a weakness-focused social influence strategy exhibited a pattern of behaviors that was "patronizing" in nature. High power men who were weakness-focused gave their female subordinates both more devalued positions and tasks (similar to those given to Black subordinates from weakness-focused participants in the current study) and much more praise (Vescio et al., 2005). We would expect similar effects in other conditions where cultural stereotypes match weakness-focused social influence strategies, as when stereotypes of Blacks match weakness-focused social influence strategies in academic contexts.

Importantly, research on social influence strategy $\times$ stereotype match effects have consistently produced evidence that the stereotype-based judgments and discriminatory acts of powerful people have adverse consequences for their low power recipients (Vescio et al., 2003, 2005). For instance, prior findings show that low power women who were treated in biased ways both reported more anger and performed more poorly than women in other conditions (Vescio et al., 2005). This raises important questions regarding the impact that the judgments and behavior of high prejudice and weaknessfocused Whites may have on their low power Black recipients. Attention to such questions is particularly important given the persistence of racial disparities in educational outcomes (Massey, Charles, Lundy, \& Fischer, 2003) and well-documented stereotype threat effects (Steele \& Aronson, 1995).

In conclusion, the present work paints a different picture of the links between power, stereotyping and discrimination than has been assumed by many recent theories. The work described in this paper, as well as other work on the social influence strategy $\times$ stereotype match effects, suggests that powerful people sometimes stereotype and sometimes do not stereotype their subordinates. Whether powerful people exhibit stereotype-based biases in their judgments about and behaviors toward low power people is not, however, the sole result of powerful people's level of motivation. Instead, the stereotype-based judgments and behaviors of powerful people vary as a function of the social influence strategies they adopt as they strive toward their goals. Powerful people will exhibit stereotypebased judgments and behavior when the cultural stereotypes of the groups to which low power people belong match and inform their goal-seeking strategies. Importantly, the construal of one's goals (or social influence strategies) can be situationally manipulated. Additional examinations of the effects of social influence strategies may be efficient and tangible ways of constraining and tempering the stereotype-based judgments and behaviors of powerful people in an array of contexts. 


\section{Acknowledgments}

This research was supported by a Penn State Research and Graduate Studies (RGSO) award to the first author. We thank Rob Franz and Laura Gelety for helpful comments on an earlier version of this paper.

\section{References}

Baron, R. M., \& Kenny, D. A. (1986). The moderator-mediator variable distinction in social psychological research: Conceptual, strategic and statistical considerations. Journal of Personality and Social Psychology, 51, 1173-1182.

Biernat, M., Vescio, T. K., \& Theno, S. (1996). Violating American values: A "value congruence" approach to understanding outgroup attitudes. Journal of Experimental Social Psychology, 32, 387-410.

Brewer, M. B. (1988). A dual process model of impression formation. In T. K. Srull, \& R. S. Wyer Jr. (Eds.), Advances in social cognition (Vol. 1, pp. 1-36). Hillsdale, NJ: Erlbaum.

Devine, P. G. (1989). Stereotypes and prejudice: Their automatic and controlled components. Journal of Personality and Social Psychology, 56, 5-18.

Diekman, A. B., \& Eagly, A. H. (2000). Stereotypes as dynamic constructs: Women and men of the past, present, and future. Personality and Social Psychology Bulletin, 26, 1171-1188.

Fiske, S. T. (1993). Controlling other people: The impact of power on stereotyping. American Psychologist, 48, 621-628.

Fiske, S. T. (2004). Social beings: A core motives approach to social psychology. New York: NY. Wiley.

Fiske, S. T., \& Neuberg, S. L. (1990). A continuum of impression formation, from category-based to individuating processes: Influences of information and motivation on attention and interpretation. In M. Zanna (Ed.), Advances in experimental social psychology (Vol. 23, pp. 1-74). New York: Academic Press.

Gaertner, S. L., \& Dovidio, J. F. (1986). The aversive form of racism. In J. Dovidio, \& S. L. Gaertner (Eds.), Prejudice, discrimination and racism (pp. 61-89). New York: Academic Press.

Glick, P., \& Fiske, S. T. (2001). An ambivalent alliance: Hostile and benevolent sexism as complementary justifications for gender inequality. American Psychologist, 56, 109-118.

Goodwin, S. A., Gubin, A., Fiske, S. T., \& Yzerbyt, V. Y. (2000). Power can bias impression processes: Stereotyping subordinates by default and by design. Group Processes and Intergroup Relations, 3, 227-256.

Jost, J. T., \& Banaji, M. R. (1994). The role of stereotyping in system-justification and the production of a false consciousness. British Journal of Social Psychology, 33, 1-27.

Katz, I., Glass, D. C., \& Cohen, S. (1973). Ambivalence, guilt, and the scapegoating of minority group victims. Journal of Experimental Social Psychology, 9, 423-436.

Katz, I., \& Hass, G. R. (1988). Racial ambivalence and American value conflict: Correlational and priming studies of dual cognitive structures. Journal of Personality and Social Psychology, 55, 893-905.

Lepore, L., \& Brown, R. (1997). Category and stereotype activation: Is prejudice inevitable? Journal of Personality and Social Psychology, 72, 275-287.

Massey, D. S., Charles, C. Z., Lundy, G. F., \& Fischer, M. J. (2003). The source of the river: The social origins of freshmen at America's selective colleges and universities. Princeton University Press: Princeton, NJ.

McConahay, J. B., Hardee, B. B., \& Batts, V. (1981). Has racism declined in America?: It depends on who is asking and what is asked. Journal of Conflict Resolution, 25, 563-579.

McConahay, J. B., \& Hough, J. C. (1976). Symbolic racism. Journal of Social Issues, 32, 23-45.

Park, B., \& Judd, C. M. (1990). Measures and models of perceived variability. Journal of Personality and Social Psychology, 59, 173-191.

Plant, E. A., \& Devine, P. G. (1998). Internal and external motivation to respond without prejudice. Journal of Personality and Social Psychology, 75, 811-832. 
Plant, A. E., \& Devine, P. G. (2003). The antecedents and implications of interracial anxiety. Personality and Social Psychology Bulletin, 29, 790-801.

Rodríguez-Bailón, R., Moya, M., \& Yzerbyt, V. (2000). Why do superiors attend to negative stereotypic information about their subordinates? Effects of power legitimacy on social perception. European Journal of Social Psychology, 30, 651-671.

Sachdev, I., \& Bourhis, R. Y. (1985). Social categorization and power differentials in group relations. European Journal of Social Psychology, 15, 415-434.

Sachdev, I., \& Bourhis, R. Y. (1991). Power and status differentials in minority and majority group relations. European Journal of Social Psychology, 21, 1-24.

Sears, D. O. (1988). Symbolic racism: Perspectives in social psychology. In D. A. Taylor, \& P. A. Katz (Eds.) Eliminating racism: Profiles in controversy (pp. 53-84). New York: Plenum.

Sears, D. O., \& Kinder, D. R. (1971). Racial tensions and voting in Los Angeles. In W. Z. Hirsch (Ed.), Los Angeles: Viability and prospects of metropolitan leadership. New York: Praeger.

Spence, J. T., \& Buckner, C. B. (2000). Instrumental and expressive traits, trait stereotypes, and sexist attitudes. Psychology of Women Quarterly, 24, 44-62.

Steele, C. M., \& Aronson, J. (1995). Stereotype threat and the intellectual test performance of African Americans. Journal of Personality and Social Psychology, 69, 797-811.

Vescio, T. K. (1996). The attributional underpinnings of stereotypes and prejudice. Unpublished dissertation. Lawrence, KS: University Kansas.

Vescio, T. K., \& Biernat, M. (1999). When stereotype-based expectancies impair performance: The effect of prejudice, race, and target quality on judgments and perceiver performance. European Journal of Social Psychology, 29, 961-969.

Vescio, T. K., Gervais, S., Snyder, M., \& Hoover, A. (2005). Power and the creation of patronizing environments: The stereotype-based behaviors of the powerful and their effects on female performance in masculine domains. Journal of Personality and Social Psychology, 88, 658-672.

Vescio, T. K., Snyder, M., \& Butz, D. A. (2003). Power in stereotypically masculine domains: A social influence strategy T stereotype match model. Journal of Personality and Social Psychology, 85, 1062-1078.

Wittenbrink, B., \& Henly, J. R. (1996). Creating social reality: Informational social influence and the content of stereotypic beliefs. Personality and Social Psychology Bulletin, 22, 598-610.

Word, C. O., Zanna, M. P., \& Cooper, J. (1974). The nonverbal mediation of self-fulfilling prophecies in interracial interaction. Journal of Experimental Social Psychology, 10, 109-120. 